\title{
COMPARISON OF OUTCOMES AFTER PERCUTANEOUS CORONARY INTERVENTION BETWEEN CALCIFIED AND NONCLACIFIED LESIONS
}

\author{
K. Satish, M. Sandeep, G. Indrani.
}

\begin{abstract}
Introduction: Coronary artery calcification increases with age and associated with significant major adverse cardiovascular events. The presence of calcification makes the percutaneous coronary interventions difficult and associated with peri-procedural complications. The main objective of our study is to evaluate the outcome of patients with calcific coronary lesions compared with non-calcific lesions.

Methods: Patients admitted in the cardiology department with either chronic stable angina or acute coronary syndrome who underwent percutaneous coronary interventions were included and divided into two groups, those who had calcific coronary lesions and non-calcific coronary lesions. Calcified lesions were made out by fluoroscopy during conventional angiogram as radiopacity at the site of the target lesion. We prospectively collected and compared the demographic, clinical data (including risk factors), details of PCI procedure and in hospital outcomes(enzymatic infarcts - EI, vascular access complications - bleed or pseudo-aneurysm, contrast induced nephropathy - CIN, target vessel acute occlusion with or without heart failure - HF and mortality ) between calcified and non-calcified lesions.
\end{abstract}

Results: A total of 439 patients were enrolled in the study of which 283 patients were in a calcific group and 156 patients were in non-calcific group. There was no significant difference among risk factors like DM and HTN ( $p=0.92$, $p=0.59)$ in between the both groups. Calcific coronary lesions had long lesions (mean lesion length $-20.01 \pm 3.8 \mathrm{~mm}$ in calcific, $18.3 \pm 3.9 \mathrm{~mm}$ in non-calcific: $p=0.00$ ) requiring longer stents (mean stent size and length- 3.08 $\pm 2.1 \mathrm{~mm}, 22.12 \pm$ $7.95 \mathrm{~mm}$ in calcific and 2.92 $0.38 \mathrm{~mm}, 20.5 \pm 7.3 \mathrm{~mm}$ in noncalcific group) compared to non-calcific lesions, which was statistically significant $(p=0.02)$. In hospital complications like EI, HF and pseudo-aneurysm were more in the noncalcific group ( $n=19, p=0.02)$, whereas vascular site bleeding was higher in the calcific group. There was no significant difference between mortality between these groups.

Article received on 22 MAR 2017, published on 30 APR 2017.

K. Satish ${ }^{1}$, M. Sandeep ${ }^{1}$, G.Indrani ${ }^{2}$

${ }^{1}$ Senior Resident, Department of Cardiology, NIMS, India

2 Ph.D. Student, Department of Cardiology, NIMS, India

Corresponding Author: K. Satish

Email: dr.satishkilli@gmail.com
Conclusion: There was no increased risk of in-hospital and peri-procedural complications in patients with calcific coronary artery lesions compared to non-calcific lesions, which also depends on other conditions like acuteness of presentation and left ventricular function.

Keywords: Calcified Lesions, Coronary Intervention.

\section{INTRODUCTION}

Coronary artery calcification (CAC) increases with age and associated with significant major adverse cardiovascular events [1]. The presence of calcification makes the percutaneous coronary interventions difficult to perform [2]. Coronary calcification prevalence is age and gender dependent with $90 \%$ of men and $67 \%$ of women with age more than 70 years $[3,4]$ People with high body mass index, uncontrolled hypertension, abnormal lipid profile (high low density lipoprotein or triglycerides, lower high density lipoprotein, or use of lipid-lowering medication), Impaired fasting glucose, untreated or treated diabetes mellitus, a familial history of coronary calcification, chronic kidney disease (CKD), higher fibrinogen level and higher C-reactive protein level are more susceptible to CAC [5].

There is a risk for stent under expansion with lower procedural success rate and a more frequent rate of acute complications, such as acute dissection and instent restenosis [6,7]. Drug eluting stents (DES) have revolutionized the field of interventional cardiology by preventing or delaying neo-intimal hyperplasia and thereby effectively lowering the rate of restenosis following coronary intervention [8].But, the data on efficacy of DES in the presence of calcium are limited. The objective of the present study was to compare the outcomes after percutaneous coronary intervention between calcified and non-calcified lesions.

\section{MATERIALS AND METHODS}

Study design and study population

Patients admitted in the cardiology department with either chronic stable angina or acute coronary 
syndrome who underwent percutaneous coronary interventions were divided into two groups, those who had calcific coronary lesions and non-calcific coronary lesions. We prospectively collected and compared the demographic, clinical data (including risk factors), details of PCI procedure and in hospital outcomes (enzymatic infarcts - EI, vascular access complications bleed or pseudoaneurysm, contrast induced nephropathy - CIN, target vessel acute occlusion with or without heart failure - HF and mortality) between calcified and non-calcified lesions.

\section{Statistical Analysis}

Continuous data are presented as mean \pm standard deviation and categorical variables are expressed as number and percentage. Baseline parameters were compared between groups using the Student $t$ test for continuous variables and the chi-square test for categorical variables. Results with a $\mathrm{p}$ value $<0.05$ is considered to be significant.

\section{RESULTS}

Total 439 patients were included in the present study, out of those 283 were in the calcified group and 156 were in the non-calcified group. The demographic variables were shown the Table 1 and Fig 1.

Table 1: Comparison of demographic parameters between two groups

\begin{tabular}{|l|l|l|l|}
\hline Parameter & Calcific & Non-Calcific & p value \\
\hline Age (Yrs) & $60.2 \pm 10.3$ & $55.9 \pm 11.8$ & 0.000 \\
\hline HTN(\%) & $176(62.2 \%)$ & $93(59.6 \%)$ & 0.59 \\
\hline DM (\%) & $129(45.5 \%)$ & $70(44.8 \%)$ & 0.92 \\
\hline SM (\%) & $36(12.7 \%)$ & $42(26.9 \%)$ & 0.000 \\
\hline Alcoholic (\%) & $18(6.4 \%)$ & $30(19.2 \%)$ & 0.000 \\
\hline CSA (\%) & $226(79.9 \%)$ & $108(69.2 \%)$ & 0.010 \\
\hline ACS (\%) & $57(20.1 \%)$ & $48(30.8 \%)$ & 0.016 \\
\hline LV Dysfunction & $71(25.1 \%)$ & $79(50.6 \%)$ & 0.000 \\
\hline
\end{tabular}

Fig 1: A clustered column chart demonstrating the parameters which are significantly different across calcific and non-calcific coronary lesions (smoking $-\mathrm{p}=0.00$, alcoholic- $\mathrm{p}=0.00$, ACS $\mathrm{p}=0.016$, LVD $\mathrm{p}=0.00$ ).

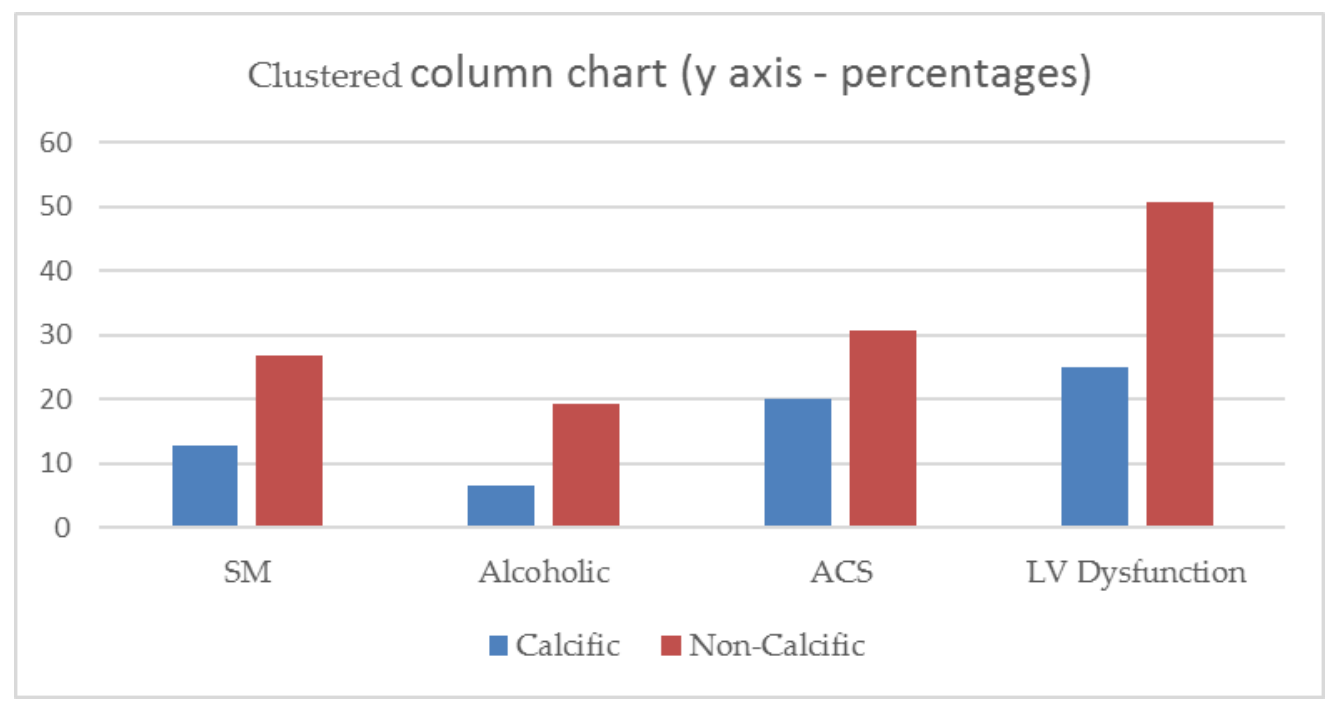

Advanced age associated with more calcified lesions $(\mathrm{p}=0.00)$. There was no statistically significant difference among risk factors like DM and HTN between calcified and non-calcified lesions $(\mathrm{p}=0.92$, 
$p=0.59)$. There was statistically significant difference between the percentage of smokers $(p=0.00)$ and alcoholics $(p=0.00)$, more in the non-calcific group compared to calcific. Patients presented with ACS ( $20.1 \%$ vs. $30.8 \%, p=0.01)$ was more in non-calcific group, whereas CSA $(79.9 \%$ vs. $60.2 \%, p=0.02)$ presentation was more in calcific group. Left ventricular dysfunction was more in non-calcific group ( $25.1 \%$ vs. $50.6 \%$, p=0.00). Comparison of angiographic parameters between calcific and non-calcific lesions was depicted in Table 2.

Table 2: Comparison of angiographic parameters between calcific and non-calcific groups.

\begin{tabular}{|l|l|l|l|}
\hline Parameter & Calcific & Non-Calcific & $\begin{array}{l}\mathbf{p} \\
\text { value }\end{array}$ \\
\hline No of Lesions & $1.41 \pm 0.56$ & $1.28 \pm 0.49$ & 0.01 \\
\hline Pre-Ref $(\mathrm{mm})$ & $2.4 \pm 0.5$ & $2.4 \pm 0.49$ & 0.92 \\
\hline Pre-MLD $(\mathrm{mm})$ & $1.04 \pm 0.37$ & $1.18 \pm 0.58$ & 0.009 \\
\hline $\begin{array}{l}\text { Pre-Lesion Length } \\
(\mathrm{mm})\end{array}$ & $20.01 \pm 3.8$ & $18.3 \pm 3.9$ & 0.000 \\
\hline Pre-Stenosis $(\%)$ & $60.58 \pm 9.6$ & $58.3 \pm 10.2$ & 0.02 \\
\hline Post MLD(mm) & $2.3 \pm 0.5$ & $2.3 \pm 0.64$ & 0.488 \\
\hline Post Stenosis $(\%)$ & $13.89 \pm 4.0$ & $14.64 \pm 5.68$ & 0.14 \\
\hline Post-Ref $(\mathrm{mm})$ & $2.7 \pm 0.5$ & $2.7 \pm 0.46$ & 0.379 \\
\hline Stent Size $(\mathrm{mm})$ & $3.08 \pm 2.1$ & $2.92 \pm 0.38$ & 0.22 \\
\hline Stent Length $(\mathrm{mm})$ & $22.12 \pm 7.95$ & $20.5 \pm 7.3$ & 0.029 \\
\hline
\end{tabular}

The average number of lesions was more in calcific group compared to non-calcific which was statistically significant. Minimal luminal diameter was less in calcific group compared to non-calcific which was statistically significant. The lesion length(mean lesion length $-20.01 \pm 3.8 \mathrm{~mm}$ in calcific, $18.3 \pm 3.9 \mathrm{~mm}$ in noncalcific: $\mathrm{p}=0.00$ ) and the required stent lengths(mean stent size and length- $3.08 \pm 2.1 \mathrm{~mm}, 22.12 \pm 7.95 \mathrm{~mm}$ in calcific and $2.92 \pm 0.38 \mathrm{~mm}, 20.5 \pm 7.3 \mathrm{~mm}$ in non-calcific group) were more in calcific group $(p=0.02)$. Comparison between the lab parameters was shown in Table 3.

Patients in the calcific group were more anemic than in the non-calcific group $(\mathrm{p}=0.02)$ and the peak CPK levels were more in the calcific group which was statistically significant $(199 \pm 861 \mathrm{IU} / \mathrm{L}$ vs. $197 \pm 674 \mathrm{IU} / \mathrm{L}, \mathrm{p}=0.02)$.
There was no statistically significant difference in the control of DM and lipid profile among both the groups. Comparison of in hospital events between both groups was shown in Table 4 \& Fig 2.

Table 3: Comparison of lab parameters between calcific and non-calcific lesions

\begin{tabular}{|l|l|l|l|}
\hline Parameter & Calcific & $\begin{array}{l}\text { Non- } \\
\text { Calcific }\end{array}$ & $\begin{array}{l}\mathbf{p} \\
\text { value }\end{array}$ \\
\hline Leucocytes (cells/mm3) & $8744 \pm 3878$ & $9188 \pm 2918$ & 0.23 \\
\hline Hemoglobin (gm/dl) & $12.35 \pm 1.62$ & $12.86 \pm 2.35$ & 0.02 \\
\hline PCV (vol \%) & $32.41 \pm 4.22$ & $34.68 \pm 5.73$ & 0.000 \\
\hline Platelet count (lakh/mm3) & $1.98 \pm 0.64$ & $2.15 \pm 0.76$ & 0.04 \\
\hline BU (mg/dl) & $32.7 \pm 17.6$ & $29.7 \pm 15.4$ & 0.07 \\
\hline Creatinine (mg/dl) & $1.14 \pm 0.70$ & $1.04 \pm 0.46$ & 0.08 \\
\hline RBS (mg/dl) & $139.6 \pm 50.5$ & $142.7 \pm 67.5$ & 0.68 \\
\hline Peak CPK(IU/L) & $199 \pm 861$ & $197 \pm 674$ & 0.02 \\
\hline Total Cholesterol (mg/dl) & $126.7 \pm 72.8$ & $110.1 \pm 44.0$ & 0.14 \\
\hline HDL (mg/dl) & $39.4 \pm 11.7$ & $40.6 \pm 11.8$ & 0.62 \\
\hline LDL (mg/dl) & $52.1 \pm 26.5$ & $45.6 \pm 23.5$ & 0.209 \\
\hline VLDL (mg/dl) & $28.8 \pm 16.6$ & $27.5 \pm 25.3$ & 0.802 \\
\hline Triglycerides (mg/dl) & $132.1 \pm 70.3$ & $123.7 \pm 72.8$ & 0.547 \\
\hline Ratio & $3.14 \pm 1.05$ & $2.87 \pm 1.01$ & 0.334 \\
\hline
\end{tabular}

Fig 2: A clustered bar chart demonstrating comparable values complications across calcific and non-calcific coronary lesions.

\section{CLUSTERED BAR CHART}

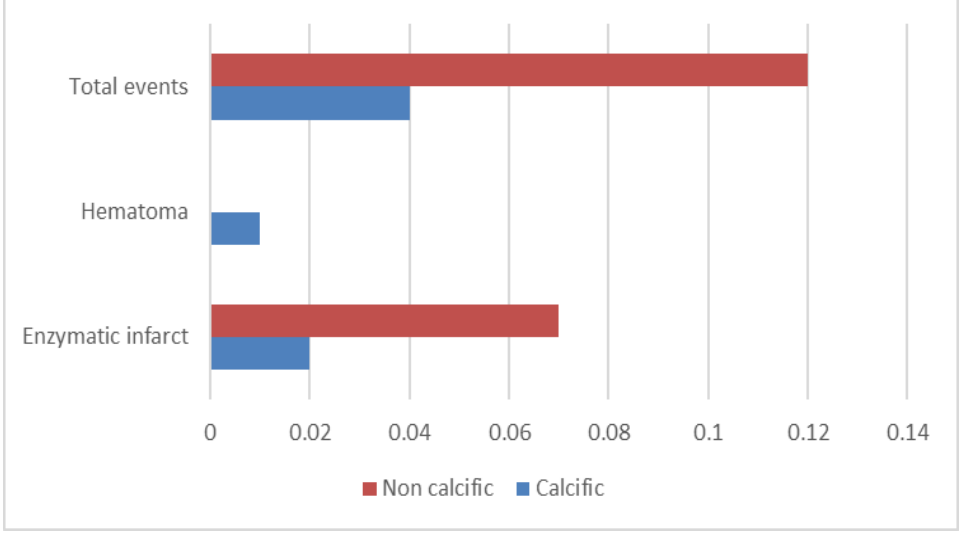


Table 4: Comparison of in hospital events between both groups

\begin{tabular}{|l|l|l|l|}
\hline In hospital events & Calcific & Non calcific & p value \\
\hline Enzymatic infarct & $6(0.02 \%)$ & $11(0.07 \%)$ & 0.026 \\
\hline Hematoma & $3(0.01 \%)$ & 0 & 0.082 \\
\hline CIN & $1(0.004 \%)$ & $2(0.01 \%)$ & 0.34 \\
\hline Pseudoaneurysm & 0 & $2(0.01 \%)$ & 0.16 \\
\hline CCF & 0 & $1(0.006 \%)$ & 0.32 \\
\hline CHB & 0 & $1(0.006 \%)$ & 0.32 \\
\hline Metabolic & 0 & $1(0.006 \%)$ & 0.32 \\
\hline Death & $2(0.007 \%)$ & $1(0.006 \%)$ & 0.94 \\
\hline Total events & $12(0.04 \%)$ & $19(0.12 \%)$ & 0.006 \\
\hline
\end{tabular}

The total number of in hospital events were more in the non-calcific coronary lesions compared with calcific lesions $(n=19, \quad p=0.02)$, which was statistically significant. Patients developing enzymatic infarct were more in non-calcific group ( 11 vs. $6, \mathrm{p}=0.02)$ vascular access complications were more in the calcific group.

\section{DISCUSSION:}

The complexity of a lesion plays an important role in the prediction of PCI outcome. The presence of calcium in an atheroma defines it as an advanced atherosclerotic lesion.

In our study advanced age was associated with more calcified lesions comparable with many other studies like Carlos et al [9], Hajime Fujimoto et al [10] and Andrew et al [11]. In our study, there was no significant difference among risk factors like DM, HTN among calcified and non-calcified lesions comparable with Hajime Fujimoto et al study [10]. In the present study smokers and alcoholics were more in non-calcific group comparable to Hajime Fujimoto et al study [10].

Acute coronary syndrome presentation was more in the non-calcific group, whereas patients with noncalcific lesions presented commonly as chronic stable angina comparable to other studies.

Patients with non-calcific coronary lesions had LV dysfunction more severe than calcific lesions, compared to Andrew et al [11], in which there was no statistically significant difference in LV function in both the groups.

In literature search we could find few studies comparing the calcified with non-calcified coronary lesions. In our study, the lesion length is more in calcific coronaries and required longer stents which was similar to the study done by Andrew et al[11]. Minimal luminal diameter was less in calcific group compared to non-calcific group. Patients in both groups underwent PCI with drug eluting stents (DES). Li et al [11], evaluated 135 patients with calcified lesions (defined as any calcification on angiography) treated with DES (sirolimus-eluting stent) and reported an incidence of target lesion revascularization-TLR of $6.9 \%$ at 8 months follow-up, which was not different from the non-calcified control group.

Kawaguchi et al [13], evaluated 152 patients with moderate or severe calcification on fluoroscopy treated with a sirolimus-eluting stent and showed a low rate of TLR (7.3\%) and MACE (13.8\%) at 12 months.

In our study, there was no restenosis complication in both the groups of patients. The total number of in hospital events were more in the non-calcific coronary lesions compared with calcific lesions. Patients developing enzymatic infarct were more in non-calcific group. Vascular access complications were more in the calcific group, as the procedure time was longer in calcific lesions compared to non-calcific lesions.

There was no significant difference in mortality between both groups in our study, compared to Andrew et al [11], in which there was higher mortality in calcified group.

\section{Limitations}

- This is a single center study with small sample size.

- Number of complications was few.

- We didn't perform grading of coronary calcium using CT coronary angiogram.

\section{CONCLUSION}

There was no increased risk of in-hospital and periprocedural complications in patients with calcific coronary artery lesions compared to non-calcific lesions, which is also dependent on other conditions like acuteness of presentation and left ventricular function.

\section{REFERENCES}

1. Kalra SS, Shanahan CM. Vascular calcification and hypertension: cause and effect. Ann Med 2012; 44 (Suppl 1): S85-S92. 
2. Greenland P1, LaBree L, Azen SP, Doherty TM, Detrano RC. Coronary artery calcium score combined with Framingham score for risk prediction in asymptomatic individuals. JAMA 2004; 291: 210215.

3. Wong ND1, Kouwabunpat D, Vo AN, Detrano RC, Eisenberg Het al. Coronary calcium and atherosclerosis by ultrafast computed tomography in asymptomatic men and women: relation to age and risk factors. Am Heart J 1994; 127: 422-430.

4. Goel M, Wong ND, Eisenberg H. Risk factor correlates of coronary calcium as evaluated by ultrafast computed tomography. Am J Cardiol 1992; 70: 977-980.

5. Richard A. Kronmal, Robyn L. McClelland, Robert Detrano, Steven Shea, João A. Lima, et al. Risk factors for the progression of coronary artery calcification in asymptomatic subjects: results from the multi-ethnic study of atherosclerosis(MESA). Circulation 2007; 115: 2722-2730.

6. Vavuranakis M, Toutouzas K, Stefanadis C, Chrisohou C, Markou D, Toutouzas P. Stent deployment in calcified lesions: can we overcome calcific restraint with high-pressure balloon inflations? Catheter Cardiovasc Interv. 2001;52(2):16472 .

7. Virmani R, Farb A, Burke AP. Coronary angioplasty from the perspective of atherosclerotic plaque: morphologic predictors of immediate success and restenosis. Am Heart J. 1994;127(1):163-79.

8. Pocock SJ, Lansky AJ, Mehran R, Popma JJ, Fahy $\mathrm{MP}, \mathrm{Na} Y$ et al. Angiographic surrogate end points in drug-eluting stent trials: a systematic evaluation based on individual patient data from 11 randomized, controlled trials. J Am Coll Cardiol. 2008;51(1):23-32.

9. Carlos M. Campos, MD; Francesco Costa, MD; Hector M. Garcia-Garcia, MD, Ph.D.; Christos Bourantas, MD, Ph.D.; Pannipa Suwannasom et al. Anatomic Characteristics and Clinical Implications of Angiographic Coronary Thrombus Insights from a Patient-Level Pooled Analysis of SYNTAX,
RESOLUTE, and LEADERS Trials. Circ Cardiovasc Interv. 2015;8:e 002279.

10. Hajime Fujimoto, MD; Masato Nakamura, MD; Hiroyoshi Yokoi, MD. Impact of Calcification on the Long-Term Outcomes of Sirolimus-Eluting Stent Implantation - Sub-analysis of the Cypher PostMarketing Surveillance Registry. Circ J 2012; 76: 57$64)$.

11. Andrew i. Macisaac, Theodore a. Bass, Maurice Buchbinder, Michael j. Cowley, Martin b. Leon, David c. Warth et al High Speed Rotational Atherectomy: Outcome in Calcified and non-calcified Coronary Artery Lesions. JAm Coll Cardiol 1995;26:731-6.

12. Li JJ, Xu B, Yang YJ, Chen JL, Qiao SB, Ma WH, Qin XW, Yao M, Liu HB, Wu YJ. Effects of sirolimuseluting stent on calcified coronary lesions. Chin Med J (Engl). 2008; 121(1):6-11.

13. Kawaguchi R, Tsurugaya H, Hoshizaki H, Toyama T, Oshima S, Taniguchi K. Impact of lesion calcification on clinical and angiographic outcome after sirolimus-eluting stent implantation inreal-world patients. Cardiovasc Revasc Med. 2008; 9(1):2-8. 